\title{
Characteristics of Conversation in Frontotemporal Dementia: Comparison with Dementia of the Alzheimer's Type
}

\author{
Jun Sang Mina, Ji Hye Yoon ${ }^{\mathrm{b}}$, Duk L. Nac, Yoonkyoung Lee ${ }^{\mathrm{b}}$ \\ ${ }^{a}$ Department of Speech-Language Pathology and Audiology, Graduate School of Hallym University, Chuncheon, Korea \\ ${ }^{b}$ Division of Speech Pathology and Audiology, Hallym University, Chuncheon, Korea \\ 'Department of Neurology, Samsung Medical Center, Sungkyunkwan University School of Medicine, Seoul, Korea
}

Correspondence: Ji Hye Yoon, PhD

Division of Speech Pathology and Audiology, Hallym University, 1 Hallimdaehak-gil, Chuncheon 24252, Korea

Tel: $+82-33-248-2224$

Fax: +82-33-256-3420

E-mail: j.yoon@hallym.ac.kr

Received: January 6, 2018

Revised: February 24, 2018

Accepted: March 6, 2018

This material is based upon work supported by the Ministry of Trade, Industry \& Energy (MOTIE) of Korea under Industrial Technology Innovation Program (No. 10063384).

This work was supported by the Hallym Leading Research Group Support Program of 2017 (No. HRF-LGR-2017-0002)
Objectives: Due to the general damage to the frontal lobe, patients with frontotemporal dementia (FTD) could have pragmatic difficulties in conversation from early stages. The purpose of this study is to investigate the characteristics of conversation in patients with FTD through a comparison with dementia of the Alzheimer's type (DAT), and then examine the relationship with general cognitive functions. Methods: Fifty subjects (FTD group $=10$, DAT group $=20$, normal adults [NA] group $=20$ ) were engaged in free conversation on various topics. Results: First, regarding conversation participation, the FTD group showed significantly lower performance than the DAT group and the NA group in the frequency of conversation turn exchanges and the number of utterances during conversation turns. Second, regarding conversation topic, the FTD group showed a significantly lower number of topics, a lower frequency of conversation turns per topic, a lower rate of topic maintenance, and a lower rate of topic switching, but a significantly higher rate of topic breakaway than the DAT group and the NA group. Third, with regard to conversation disturbance, the FTD group did not show a significant difference in performance from the DAT group or the NA group. Conclusion: It is possible that FTD patients displayed a smaller number of utterances due to lack of motivation caused by the damage to the medial frontal lobe and have difficulties in topic maintenance and various topic initiation due to dysfunction of general language processing abilities and working-memory capacity caused by the damage to the dorsolateral area.

Keywords: Frontotemporal dementia, Conversation, Topic management, Topic maintenance
치매란 다양한 원인으로 인지기능이 소실되는 경우를 말하며, 기억력이 감퇴하거나, 정서 및 성격, 행동이상 등의 증상은 사회생 활과 타인과의 상호작용에서 어려움을 초래한다(Diagnostic And Statistical Manual of Mental Disorders-Fourth Edition, DSM-IVTest Revised, 2000). 치매에는 전체 치매 중 약 $72 \%$ 를 차지하는 알 츠하이머성 치매(dementia of the Alzheimer's type, DAT)가 가장 흔하며 혈관성치매(vascular dementia, 17\%)와 전두측두엽 변성 (frontotemporal lobar degeneration, FTLD)으로 인한 치매(5\%)가 그 뒤를 잇고 있다(Health Insurance Review \& Assessment Service, 2016). FTLD의 아형 중 하나인 전두측두치매(frontotemporal de- mentia, FTD)는 측두엽과 전두엽의 퇴행으로 인해 병의 초기부터 인격 변화, 비정상적인 행동이 두드러지며(Neary, Snowden, Northen, \& Goulding, 1988). 이러한 증상은 환자뿐만 아니라 보호자에 게도 신체적, 정신적, 경제적인 부담을 준다. $\mathrm{FTD}$ 를 포함한 여러 치 매는 완치가 어려우므로 발병 전 예방이나 조기 감별이 중요하며 이를 통하여 적절한 치료가 제공되어야 한다. 그러나, 위에서 언급 한 FTD의 행동 변화나 정서 변화는 다른 정신질환에서도 나타나는 행동 변화와 유사성이 많기 때문에(Jun \& Park, 2016) 진단 시 행동 변화이외의 추가적인 감별 정보를 확인하는 과정이 요구된다.

이에 FTD의 행동 변화 이외에 다른 영역에서의 변화를 확인하 
고 그 특성을 기술하고자 하는 시도가 있어왔고, 인지 언어 측면에 서는 특정 하위 능력의 변화에 대한 선행연구들이 이루어졌다. FTD의 언어능력에 대한 선행연구들을 살펴보면, 구어 측면에서는 통제된 과제에서 전두엽 기능장애로 인하여 명사이름대기보다 인 지적 기술이나 집행기능에 좀 더 의존적이며 구문적인 처리를 필 요로 하는 동사이름대기에서 더 어려움을 보였고(Cappa et al., 1998; Cotelli et al., 2006; Grossman et al., 1996) 문어 측면에서는 단순 관찰 및 증례보고를 통하여 소문자에 비하여 대문자 쓰기에 어려움을 보이는 이서실서증(allographic agraphia)이나 글씨의 구 성 오류를 보이는 실행실서증(apractic agraphia) 양상이 보고되었 다(Menichelli, Rapp, \& Semenza, 2008).

이렇게 특정 하위 언어능력들의 변화도 중요하지만 보다 일상의 언어를 반영하는 담화, 특히 대화 능력은 일상의 의사소통 상황에 서 개인의 의도를 전달하고 정보를 얻거나 공유하고, 타인과의 상 호작용을 가능케 한다는 측면에서(Abbeduto \& Hesketh, 1997; Bryan, Donahue, Pearl, \& Sturm, 1981; Choi \& Jeon, 2003; Craig \& Evans, 1989; Edmonds \& Haynes, 1988; Heo \& Lee, 2012; Hong, Heo, \& Lee, 2012; Kim \& Lee, 2007; Lee \& Kim, 2001) 사회적 관계 형성에 중요한 역할을 한다. 대화 능력에는 의미, 음운, 구문 등 언어 의 기초적인 기술과 더불어 화자의 대화 상황과 관련된 지식, 청자 가 필요로 하는 사회적 지식에 대한 전제 기술, 청자를 위해 새로운 문맥의 설명을 포함한 참조적 기술 등 상대와의 관계를 파악하고 대화가 이루어지는 상황의 맥락을 파악하는 등의 능력이 필요하다 (Mentis, 1994; Owens, 2004). 이러한 언어적 기술이나활용적인 측 면을 가리키는 화용은 언어, 인지, 운동감각적 과정의 상호작용에 의한 기능적이며 맥락적인 언어 사용을 의미한다(Perkins, 2005). 따라서, 의사소통 상황에서 발생하는 다양한 개념의 통합과 추상 적인 사고의 사용을 요구하므로 고차원적 의미에 대한 이해나 표 현과 관련된다(Lee \& Kim, 2013). 인간의 전두엽은 개념 통합과 관 련된 조직화 능력, 추상적인 사고에 필요한 추론력, 복잡한 언어의 이해와 관련된 문제해결력, 집행기능 등의 다양한 상위 인지기능 을 담당한다(Channon \& Watts, 2003; Douglas, Bracy, \& Snow, 2007). 이들 중 집행기능은 과제 수행 시에 주의력을 할당하며, 정 보를 유지하거나 조작하고, 과제의 계획 및 실행을 총괄하는 인지 적 통제 과정으로서 화용언어 능력과 필연적으로 직결된다(Douglas, 2010; Miller, 2000). 이러한 맥락에서, FTD 환자는 전두엽 기능 의 감퇴로 인해 초기부터 대화에서 화용적 어려움을 보일 수 있다 (Mikesell, 2010).

이들은 주제에서 벗어난 발화, 체계적이지 않은 발화를 보이거나 작화증, 반복 등의 양상을 보이고(Orange, Kertesz, \& Peacock, 1998;
Mikesell, 2010; Tallberg, 2007) 상대방과의 이야기가 길어지거나 논리적 담화 상황에서 심각한 어려움을 호소한다(Ash et al., 2006; Cosentino, Chute, Libon, Moore, \& Grossman, 2006). 상기의 선행 연구들은 대부분 가정에서 일반적인 대화 상황을 녹화하여 그 양 상을 간단히 기술한 증례보고로 이루어졌다(Mikesell, 2010; Tallberg, 2007). 그러나 대화는 주제나 대화 상대자에 따라 영향을 받 을 수 있으므로 이러한 연구결과를 $\mathrm{FTD}$ 의 대화 특성으로 일반화 하기에는 어려움이 있고, 언어 특성을 세밀히 확인하기 위해서는 관찰에 근거한 증례보고가 아닌 체계적인 분석을 통한 접근이 필 수적이다. 따라서 대화 특성을 체계적으로 확인하기 위해서 자연스 러운 대화 상황에서도 일관적인 대화 유도 절차를 통해 대화 상대 자 요인을 통제하는 것이 필요하며 이러한 절차를 통해 FTD 환자 의 대화 특성을 보다 신뢰롭게 관찰할 수 있다.

더불어 FTD 환자들은 정서 및 행동장애를 주 특징으로 하나, 인 지기능 장애를 동반하는 퇴행성 질환이기 때문에 대화에서 나타 나는 어려움이 기억력을 포함한 전반적인 인지기능 저하의 문제 때 문인가를 감별할 필요가 있다. DAT 환자들은 인지기능의 저하를 보이는 대표적인 치매환자로서 기본적인 일상생활 활동에 어려움 을 보인다. 이들은 초기에 주로 측두엽과 두정엽에 손상을 보인다. 따라서 병의 초기부터 기억력, 집행기능, 주의력, 지각, 시공간 능력 저하 등의 인지기능 장애가 나타난다(Yoon, Jeong, Kang, \& Na, 2000). 또한 타인과의 상호작용에 있어 청자의 요구에 적절하게 반 응하지 못하기 때문에 원활한 대화에 어려움을 보인다(Müller \& Guendouzi, 2005). 즉, 화자가 원하는 발화를 적절히 산출하지 못 하면서 화행 능력에 어려움을 보이게 되며 이는 전반적인 의사소통 의 효율성을 저하시킨다(Carlomagno, Santoro, Menditti, Pandolfi, \& Marini, 2005). 대화 시에 다양한 주제를 표현하지 못하며 같 은 내용을 반복하거나 의미 없는 발화들을 산출하거나(Vuorinen, Laine, \& Rinne, 2000; Müller \& Wilson, 2008) 주어진 정보를 분석 하여 문맥에 맞는 발화를 산출하는 능력이 저하되며(Braver, Satpute, Rush, Racine, \& Barch, 2005) 자주 주제에서 벗어나는 발화 들을 보이고 주제 간의 응집성이 체계적이지 못하다(Müller \& Wilson, 2008). 이들은 지시물을 정확하게 유추하는 능력이 저하 되어 대화 내에서 지시물이 모호한 양상을 보이기도 한다(Müller \& Guendouzi, 2005; Müller \& Wilson, 2008). 이처럼 대화 내에서 다 양한 오류 양상을 보이는 DAT와의 비교를 통하여 FTD 환자들의 대화 특성이 전반적인 인지기능 감퇴에 기인한 것인지 전두엽 기능 부전에 기인한 독특한 양상인지를 감별하기 위하여 DAT 환자들 의 대화특성과 비교할 필요가 있다. 이에, 본 연구에서는 전두측두 치매 환자와 정상 성인과의 비교를 통해 대화참여 지표와 대화화 
Jun Sang Min, et al. • Characteristics of Conversation in Frontotemporal Dementia

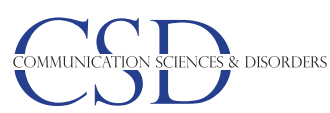

제 지표 및 대화방해 지표 특성을 확인하고 DAT와의 비교를 통해 전반적인 인지기능과의 관계를 다각도로 살펴보고자 하였다.

\section{연구방법}

\section{연구대상}

본 연구는 40-90세에 해당하는 전두측두치매 환자(FTD) 10 명, 알츠하이머성 치매 환자(DAT) 20명, 정상 성인(NA) 20명을 대상 으로 하였다. 정상 성인은 서울 및 강원지역에서 모집하였으며, 건 강선별설문지(Christensen, Multhaup, Nordstrom, \& Voss, 1991) 를 시행하여 인지능력에 영향을 줄 수 있는 정신적 혹은 신경학적 이상이 없고 말-언어장애의 과거력이 없으며 시력과 청력이 정상인 경우에만 포함하였다. 또한, 단축형 노인우울척도(Short form Geriatric Depression Scale, SGDS; Kee, 1996)와 한국판 간이정신상 태검사(Korean Mini-Mental State Examination, K-MMSE; Kang, 2006)를 실시하여 우울감이 없으며, 연령과 학력에 맞는 정상 범주 의 인지기능을 가진 대상자로 선정하였다.

전두측두치매 환자는 대학병원 신경과 전문의로부터 Rascovsky 등(2011)의 진단 기준을 통해 FTD로 진단된 대상자로 하였다. 진단 기준을 살펴보면, 반드시 점진적으로 진행하는 행동장애 또는 인 지기능 저하의 병력을 가지며 possible 행동 변이형 전두측두치매 의 경우 행동 탈억제, 무감정 혹은 무기력, 동정 또는 공감 소실, 충 동적 행동, 식이 변화 그리고 전반적 수행기능 저하를 보이나 기억 력이나 시공간 기능은 유지됨 등의 증상 중 세 가지 이상이 동반될 경우로 하였다.

DAT 환자는 National Institute of Neurological and Communicative Disorders and Stroke and Alzheimer's Disease and Related Disorders Association (NINCDS-DATRDA criteria)상 probable DAT 기준(Dubois et al., 2007)에 해당하는 환자들을 대상으로 하 였다.

환자군의 경우 퇴행성 치매로 진단받았기 때문에 인지능력의 저 하로 인하여 전반적인 과제 이해에 어려움이 있을 수 있다. 이에 국 내 치매 환자군을 대상으로 한 선행연구들을 참고하여(Choi, 2010; Kim, Kim, Namkoong, Kim, \& Kim, 2006; Kim, 2012; Lim et al., 2014; Oh, Choi, \& Kim, 2010) Clinical Dementia Rating (CDR; Morris, 1993) 0.5-2점 사이, Global Dementia Scale (GDS; Choi et al., 2002) 5점 이하의 경중도(mild to moderate)에 해당하는 환자들 로 선정하였다. 연구에 참여한 연구대상 정보는 Table 1에 제시하였 다. 세 집단의 연령, 학력 및 K-MMSE 점수를 비교한 결과, 연령 $(p=.169)$ 및 학력 $(p=.345)$ 에서는 집단 간 유의미한 차이가 없었다.
Table 1. Participants' information

\begin{tabular}{lccc}
\hline & FTD group ( $\mathrm{N}=10)$ & DAT group ( $\mathrm{N}=20)$ & NA group ( $=20)$ \\
\hline Age (yr) & $71(5.91)$ & $71.6(7.1)$ & $68.6(2.1)$ \\
Education (yr) & $9.71(4.82)$ & $12.2(3.2)$ & $11.7(2.0)$ \\
K-MMSE & $20(4.2)$ & $20.8(2.9)$ & $27.5(1.1)$ \\
CDR & $.75(.48)$ & $.95(.77)$ & \\
GDS & $4.1(.8)$ & $4.3(.6)$ & \\
\hline
\end{tabular}

Values are presents as mean (SD).

FTD= frontotemporal dementia; DAT = dementia of the Alzheimer's type; NA=normal adults.

$\mathrm{K}-\mathrm{MMSE}$ 점수에서는 NA와 FTD 집단 $(p<.001), \mathrm{NA}$ 와 DAT 집단 $(p<.001)$ 간 유의한 차이가 있었으며, DAT와 FTD 집단 $(p=.558)$ 간의 K-MMSE 점수 차이는 유의하지 않았다.

\section{자료수집 도구 및 절차}

Wetherby와 Rodriguez (1992)는 대화 수집 시 구조화된 절차와 자연스러운 상황을 동시에 고려해야 한다고 하였다. 이에 선행연구 에서는 ‘학교생활' , '취미생활', '가족소개'와 같이 일상적으로 친숙 한 화제를 제시하고 구조화된 절차를 통해 대화를 수집하였다 (Brinton, Fujiki, \& Powell, 1997; Evans \& Craig, 1992). 국내의 장 애아동을 대상으로 한 선행연구(Choi \& Lee, 2013, 2015; Heo \& Lee, 2012; Hong \& Lee, 2016)에서도 검사자 간 일관성 있는 대화수 집을 위하여 대화 화제나 절차가 구조화되었으며 이를 통해 '한림 대화·화용프로토콜(Lee \& Choi, 2018)' (Appendix 1)이 수정 및 개 발되었다(Park, Choi, \& Lee, 2017). 이 프로토콜은 대화자료 수집 시 세 가지의 동일한 주제('학교생활', '가정생활' '친구 이야기')와 구조화된 대화 유도 절차를 일관된 방법으로 제시하는 것으로 청 각장애, 자폐성범주장애, 지적장애 등, 장애 집단의 대화 연구(Choi \& Lee, 2013, 2015; Heo \& Lee, 2012; Hong \& Lee, 2016)를 통해 그 신뢰성이 검증되었다. 따라서 본 연구에서는 '한림 대화·화용프로 토콜’의 대화 유도 절차를 사용하였다. 단, 연구참여자가 모두 성인 대상자임을 고려하여 '학교생활' 주제를 '여가생활' 주제로 변경하여 '가정생활, 여가생활, 친구 이야기'를 대화 주제로 최종 선정하였다. 대상자의 발화를 유도하기 위해 대상자와 검사자가 1:1로 조용한 방에서 15-20분 동안 대화 과제를 실시하였다. 대화 자료수집 시, '가정생활'과 '여가생활'의 경우 주제와 관련된 사진을 주제별로 각 각 4장씩 제시하고, '친구 이야기' 주제는 사진자료 없이 구어로 주제 를 제시하였다. 각 사진의 크기는 가로 $220 \mathrm{~mm}$, 세로 $170 \mathrm{~mm}$ 였다.

과제는 대화를 진행하기 전, 대상자에게 녹음 및 연구 진행과정 에 대한 사전 동의를 받은 후 대화를 실시하였다. 모든 대화는 녹음 기(ICD-UX560F)를 사용하여 녹음하였다. 자세한 한림 대화·화 
용프로토콜의 수집 절차는 다음과 같다.

1) 대상자들에게 2개의 봉투에 각각 통일된 주제의 사진이 4장씩 있으며, 봉투를 하나씩 선택하여 차례대로 그 주제와 관련된 대화를 할 것이라고 설명하였다.

2) 대상자가 과제를 이해했다고 생각되면, 봉투를 선택하게 한 후, 4 장의 사진을 꺼내어 차례대로 보고 관련된 주제로 개시할 기회를 주었다.

3) 대상자가 3초 내에 스스로 대화를 시행하지 않는 경우 "가정 생활과 관련된 사진이지요", 혹은 “여가생활과 관련된 사진이 지요"와 같이 사진의 주제를 언급하였다.

4) 주제를 언급해줘도 무반응인 경우 “가정생활은 어떠세요?”, “여가생활은 어떠세요?” 와같이 주제와 관련된 질문을 하였다.

5) 대상자가 대화를 이어갈 경우 연구자는 발화를 반복해주거나 “네, 맞아요”, “그렇죠”와같이 중립적으로 반응하였다.

6) 대상자가 대화를 이어나가지 못하거나 2-3초 정도 쉼을 보이 면, 발화를 이어나갈 수 있도록 “그리고요?”, “또요?”와 같은 질문을 제공하여 촉진하였다.

7) 검사자의 촉진발화(그리고요?, 또요?)를 제공해주어도 3초 이 내에 반응이 없거나 대상자가 끝맺는 말, 더 이상 할 말이 없다 는 행동(“없어요, 끝이에요 등”, 무반응)을 하면 3초 정도 쉬었 다가, 대상자가 이야기하지 않았던 내용의 사진을 보여주며 질 문하고 5)번과 6)번의 절차대로 진행하였다.

8) 각 주제에서 모든 질문에 대해 대상자가 끝맺음 말이나 할 말 이 없다는 듯한 행동을 보이면 3초 정도 쉬었다가 남은 봉투를
주고 다른 주제를 고르게 하여 앞의 절차와 같이 대화를 진행 하였다.

9) 두 주제가 완료되면 사진 없이 3개의 '친구 이야기' 질문을 한 후, 앞의 절차와 동일하게 대화를 진행하였다.

\section{자료 전사 및 분석}

대화 자료는 자료수집 상황에서 녹음한 내용을 바탕으로 일주 일 이내에 전사하였다. 발화는 Kim (1997)의 발화 구분 원칙(Appendix 2)에 따라 전사되었으며 Heo와 Lee (2012)의 분석 기준 (Appendix 3)에 따라 대화차례를 구분하였다. 또한, Schober-Peterson과 Johnson (1993)의 분석 기준(Appendix 4)을 참고하여 전 체 주제 수를 분석하였으며 Park 등(2017)이 제시한 분류 기준을 참고 및 보완하여 주제 운용 기술의 유형을 구분하였다(Appendix 5). 또한, 전두측두치매 환자의 특성상 전두엽 손상으로 인한 사회 적 상호작용 능력과 관련된 사회적 지식과 기술의 어려움이 대화 내에서 얼마나 방해를 보이는지 확인하기 위해 대화방해(Appen$\operatorname{dix}$ 5)를 측정하였다. Kim과 Lee (2007)를 참고하여 전사된 발화 중 알아듣지 못하거나 이해할 수 없는 발화, 대상자가 말하는 동안 연구자가 개입하여 중첩된 발화, 혹은 자동적인 발화같이 화용적 으로 분류되지 않는 발화는 분석에서 제외되었다. 전사된 발화 자 료는 크게 3 가지 측면인 대화참여, 화제, 방해 지표의 측면으로 나 누어 분석하였다. 참여 지표는 대화차례 빈도, 대화차례당 발화 수 를 분석하였다. 화제 지표는 화제 수, 화제당 대화차례 빈도, 화제유 지비율, 화제전환비율, 화제이탈비율을 분석하였다. 방해 지표는

Table 2. Measurement of conversation performance

\begin{tabular}{ll}
\hline Frequency of turn-taking & Total frequency of turn-takings \\
Number of utterances per turn & Total utterances/Total frequency of turn-takings \\
Number of topics & Number of total topics \\
Turns per topic & Total topics/Total frequency of turn-takings \\
$\%$ of topic maintenance & (Total topic maintenance/Total frequency of turn-takings) $\times 100$ \\
$\%$ of topic switching & (Total topic switch/Total frequency of turn-takings $) \times 100$ \\
$\%$ of topic breakaway & (Total topic breakaway/Total frequency of turn-takings $) \times 100$ \\
$\%$ of turn reiteration & (Total reiteration/Total frequency of turn-takings) $\times 100$ \\
\hline of turn interruption & (Total interruption/Total frequency of turn-takings $) \times 100$ \\
\hline
\end{tabular}

Table 3. Results of ANOVA in conversation participation indexes

\begin{tabular}{lcccrrr}
\hline & FTD group & DAT group & NA group & $F$ & $p$-value \\
\hline Frequency of turn-taking & $18.5(4.3)$ & $38.3(10.3)$ & $42.7(14.3)$ & 16.416 & $<.001^{*}$ \\
Number of utterances per turn & $1.07(.12)$ & $1.5(.2)$ & $1.6(.7)$ & 5.260 & $.009^{*}$ \\
\hline
\end{tabular}

Values are presented as mean (SD).

FTD = frontotemporal dementia; DAT = dementia of the Alzheimer's type; NA=normal adults. ${ }^{*} p<.05$. 
대화차례 중첩비율, 중단비율을 분석하였다. 각각에 대한 측정방 법은 Table 2에 제시하였다.

\section{신뢰도}

신뢰도 검증을 위하여 제 2 연구자로 언어병리학 석사과정생 1 명 을 선정하였다. 제 2 연구자에게 검사, 기록, 분석방법을 설명한 후 무작위로 데이터의 $20 \%$ 를 분석하도록 하였다. 연구자와 제 2 연구 자 간의 일치율을 확인한 뒤, 일치하지 않은 부분에 대해서는 논의 후 의견 조율을 통해 합의하였다. 신뢰도 측정은 연구자와 제 2 연구 자가 통일된 반응의 수를 통일된 반응의 수와 통일되지 않은 반응 의 수로 합하여 나눈 후 100 을 곱하여 구하였다. 그 결과 검사자 간 일치율은 $95 \%$ 였다.

\section{연구결과}

\section{집단 간 대화참여 지표 차이}

FTD, DAT, NA 집단 간 대화차례 주고받기, 대화차례 주고받기 당 발화수에 대한 분산분석 결과는 Table 3에 제시하였다.

분산분석 결과 대화프로토콜 진행 동안 대화차례 빈도 $(F=16.416$, $p<.001)$ 와 대화차례당 발화 수 $(F=5.260, p=.009)$ 모두 유의미한 차이가 나타났다. 대화차례 빈도와 대화차례당 발화 수가 어떤 집 단에서 차이를 보였는지 알아보기 위해 Scheffe 사후분석을 실시하 였다. 그 결과, FTD 집단이 대화차례 빈도수에서 DAT 집단 $(p<.001)$ 과 NA 집단 $(p<.001)$ 에 비해 유의미하게 낮았다. FTD 집단이 대화 차례당 발화 수에서 DAT 집단 $(p=.041)$ 과 NA 집단 $(p=.010)$ 에 비 해 유의미하게 낮았다. 반면에, DAT 집단은 NA 집단과 비교하여 대화차례 빈도( $p=.432)$ 와 대화차례당 발화 수( $p=.789)$ 에서 유의 미한차이가 없었다.

\section{집단 간 대화화제 지표 차이}

FTD, DAT, NA 집단 간 화제 수, 화제당 대화차례 빈도, 화제유지
비율, 화제전환비율, 화제이탈비율에 대한 분산분석 결과는 Table 4에 제시하였다.

분산분석 결과 대화프로토콜 진행 동안 화제 수 $(F=10.323, p<$ $.001)$, 화제당 대화차례 빈도 $(F=11.775, p<.001)$, 화제유지비율 ( $F=52.257, p<.001)$, 화제전환비율 $(\mathrm{F}=5.997, p=.005)$, 화제이탈 비율 $(F=52.648, p<.001)$ 에서 집단 간 유의미한 차이가 나타났다. 화제 수, 화제당 대화차례 빈도, 화제유지비율, 화제전환비율, 화제 이탈비율이 어떤 집단에서 차이를 보였는지 알아보기 위해 Scheffe 사후분석을 실시하였다.

그 결과, FTD 집단이 화제 수에서 DAT 집단 $(p=.012)$ 과 NA 집단 $(p<.001)$ 에 비해 유의미하게 낮았으며 화제당 대화차례 빈도에서 도 DAT 집단 $(p<.001)$ 과 $\mathrm{NA}$ 집단 $(p<.001)$ 에 비해 유의미하게 낮 았다. FTD 집단이 화제유지비율에서 $\mathrm{DAT}$ 집단 $(p<.001)$ 및 $\mathrm{NA}$ 집 단 $(p<.001)$ 에 비하여 FTD 집단이 유의미하게 낮았으며, 화제전환 비율에서는 DAT 집단 $(p=.016)$ 및 NA 집단 $(p=.004)$ 에 비하여 유 의미하게 낮았다. 마지막으로 화제이탈비율에서는 DAT 집단 $(p<$ $.001)$ 과 NA 집단 $(p<.001)$ 에 비해 FTD 집단이 유의미하게 높았다.

반면에, DAT 집단은 화제 수( $p=.226)$, 화제당 대화차례 빈도 ( $p=.988)$, 화제유지비율 $(p=.900)$, 화제전환비율 $(p=.839)$, 화제이 탈비율 $(p=.892)$ 모두 NA 집단과 비교하여 유의미한차이가 없었다.

\section{집단 간 대화방해 지표 차이}

FTD, DAT, NA 집단 간 대화차례 중단비율과 중첩비율에 대한 분산분석 결과는 Table 5 에 제시하였다. 분산분석 결과 대화프로

Table 5. Results of ANOVA in conversation disturbance indexes

\begin{tabular}{lccccc}
\hline & FTD group & DAT group & NA group & $F$ & $p$-value \\
\hline \% of turn reiteration & $.7(2.21)$ & $0(0)$ & $0(0)$ & 2.089 & .135 \\
$\%$ of turn interruption & $0(0)$ & $0(0)$ & $0(0)$ & & \\
\hline
\end{tabular}

Values are presented as mean (SD).

FTD=frontotemporal dementia; DAT = dementia of the Alzheimer's type; NA=normal adults.

${ }^{*} p<.05$.

Table 4. Results of ANOVA in conversation topic indexes

\begin{tabular}{|c|c|c|c|c|c|}
\hline & FTD group & DAT group & NA group & $F$ & $p$-value \\
\hline Number of topics & $17(2.98)$ & $23.8(5.82)$ & $27(6.4)$ & 10.323 & $<.001^{*}$ \\
\hline Turns per topic & $1.08(.09)$ & $1.56(.31)$ & $1.59(.35)$ & 11.775 & $<.001^{*}$ \\
\hline$\%$ of topic maintenance & $77.4(12.33)$ & $98.05(2.87)$ & $98.9(1.99)$ & 52.257 & $<.001^{*}$ \\
\hline$\%$ of topic switching & $0(0)$ & $1.25(.96)$ & $1.45(1.46)$ & 5.997 & $.005^{*}$ \\
\hline$\%$ of topic breakaway & $21.9(11.79)$ & $1.95(2.87)$ & $1.1(1.9)$ & 52.648 & $<.001^{*}$ \\
\hline
\end{tabular}

Values are presented as mean (SD).

FTD = frontotemporal dementia; DAT = dementia of the Alzheimer's type; NA=normal adults. ${ }^{*} p<.05$. 
토콜 진행 동안 대화차례 중단비율 $(F=2.089, p=.135)$, 중첩비율 모두에서 집단 간 유의미한 차이를 보이지 않았다.

\section{논의 및 결론}

본 연구에서는 FTD 환자의 대화능력을 살펴보기 위해 NA 집단 과 FTD 환자군 간의 대화 능력을 대화 참여지표, 화제지표, 방해지 표로 나누어 비교하였고, 이러한 대화능력이 전반적인 인지기능 저 하와 어떠한 관계가 있는지 확인하기 위하여 DAT 환자의 대화능 력과도 비교하였다.

\section{집단 간 대화참여 지표(대화차례 주고받기 빈도, 대화차례당 발화 수) 비교}

대화차례 주고받기 빈도에서 FTD 환자들은 다른 두 집단군에 비 하여 평균 빈도가 적어 대화에 참여한 양이 적은 것으로 나타났다. 또한, 한 번의 대화차례에서 얼마나 길게 이야기하는지를 반영하는 대화차례당 발화 수에서 FTD 환자들이 다른 두 집단군에 비하여 평균 대화차례당 발화 수가 적은 것으로 나타났다. 본 연구에 포함 된 FTD 환자들은 $\mathrm{CDR}$ 평균 0.75 ( \pm 0.45$)$, GDS 평균 4.1 ( \pm 0.8 )에 해당되어 비교적 경도의 환자들이었으므로 이러한 결과는 FTD 환 자들이 초기부터 대화 시 발화량이 감소되고 무동성 함묵증을 보 일 수 있다고 한 선행연구들과 일치하는 결과이다(Mikesell, 2010; Orange et al., 1998; Tallberg, 2007).

FTD 환자의 대화량이 적은 것은 대상자들의 전두엽 내측 부위 손상과 관련하여 해석해볼 수 있다. 전두엽 내측 부위는 자발성 및 동기와 같은 기능들을 담당한다고 알려져 있으며, 내측 부위가 손 상될 경우 자신의 일과 책임에 대한 흥미를 상실하거나 사회적으로 위축되는 모습을 보인다. 이들은 정서적인 무관심과 무감동이 흔하 게 나타나며 공감능력이 부족하여 타인의 감정을 공감하는 것에 어려움을 보인다(Cummings, 2003). 이러한 양상들은 언어의 측면 에서 초기부터 점차 말이 적어지면서 함묵증(mutism)을 보이는 형 태로 반영될 수 있다(Cummings, 1993; Cummings et al., 1994; Duffy \& Campbell, 1994). 물론 DAT 환자에서도 우울증으로 인해 과제 수행 시 수행에 소극적인 자세를 취하게 하면서 과제의 수행력 에 영향을 주기도 한다(Perry et al., 1981). 그러나, FTD에서의 우울 증은 흔하지 않다고 알려져 있으므로(Swartz et al., 1997) 대화 과제 수행 시에 관찰된(Appendix 6) 것처럼 무반응 혹은 무관심과 같은 소극적인 자세는 자발성이나 동기의 감소로 인하여 대화프로토콜 을 진행하는 동안 대화에 참여하고자 하는 의지 저하가 반영되었 을 가능성이 있고, 그로 인하여 전체적으로 짧은 발화로만 말하거
나 혹은 다른 두 집단에 비하여 말수가 현저하게 적어진 모습을 보 이게 한 것으로 해석해볼 수 있다. 그러나 본 연구대상자에게 우울 증에 대한 심화검사를 시행하지 않았으므로 추후 연구를 통하여 발화량 감소가 어떠한 원인에 기인한 것인지를 확인할 필요가 있다.

\section{집단 간 대화화제 지표(화제 수, 화제당 대화차례 빈도, 화제유지비율, 화제전환비율, 화제이탈비율) 비교}

첫째, 대화프로토콜 내에서 얼마나 다양한 화제로 이야기하는지 를 반영하는 화제 수에서 FTD환자들이 다른 두 집단군에 비하여 유의하게 낮은 수의 화제를 산출하였다. 이러한 결과는 FTD 환자 들이 다양한 정보들을 개시하는 데 어려움을 보일 수 있다고 한 선 행연구들과 일치하는 결과이다(Damasio \& Anderson, 1993; Duffy \& Campbell, 1994; Filley, 1995). 어떠한 행동을 개시하는 것은 동기 나 의도가 있어야 할뿐만 아니라 정상적인 집행기능의 수행과도 관 계가 있다. 집행기능은 다른 인지적 기능들을 통제하는 심리적 기 능으로서 하고자 하는 행동을 계획하거나, 개시 및 종료, 행동규칙 습득 등을 총괄하는 고차원적 인지기능이며 이러한 집행기능은 대뇌의 전두엽 배외측 피질에서 담당하는 것으로 알려져 있다. 대 화에 있어서 다양한 화제를 개시하기 위해서는 제시된 과제에 대 한 정보를 분석하고 조작하여 다양한 사고를 계획하고 개시할 수 있어야 하며 이는 집행기능에 포함된다. 결과적으로 FTD 환자들 은 전두엽 손상으로 인한 집행기능의 저하로 판단력이 저하되고 정 보를 조작하며 과제의 계획 및 실행을 총괄하는 인지적 통제 과정 이 저하되면서(Douglas, 2010; Miller, 2000; Channon \& Watts, 2003) 추론하거나 계획하는 능력의 상실을 보이기 때문에 다른 두 집단군에 비하여 다양한 화제를 개시하지 못하였다고 볼 수 있다. 유사한 맥락에서 주의력결핍 과잉행동장애 아동의 연구(Luo \& Timeler, 2008)를 통하여 아동이 대화에서 개시의 어려움을 보이 는 이유가 손상된 집행기능으로 인하여 이야기를 도식화하고 조작 하지 못하는 것에 기인함으로 해석하였으나 FTD 집단에서 집행기 능과 대화능력의 관계를 직접 다룬 선행연구는 없으므로 본 결과 해석에 주의할 필요가 있다.

둘째, FTD 환자들은 대화프로토콜 내에서 하나의 주제로 얼마 나응집력 있게 대화를 끌어나가는지를 반영하는 화제당 대화차례 빈도, 화제유지비율, 화제전환비율, 화제이탈비율에서 다른 두 집 단군에 비하여 유의하게 저하된 수행력을 보였다. 화제당 대화차례 빈도에서 보인 수행력 저하는 위에서 언급하였듯이 대화참여에 대 한 의지 저하로 인해 연구자가 제시한 주제에 대해 무반응을 보이 거나 짧은 발화로만 대답하여 나타난 결과라고 볼 수 있다. 화제유 지비율과 화제전환비율이 낮았던 결과는 FTD 환자들이 담화 수 
준에서 통일성 및 주제 유지에 어려움을 보였다고 할 수 있다(Assal \& Ghika, 2013; Mikesell, 2010; Orange et al., 1998; Tallberg, 2007). 즉, FTD 환자들은 주어진 주제에 대하여 상대방과 대화차례를 주 고받으며 대화를 하지만 대화차례 사이에 관련 없거나 모호한 내 용으로 말하여 주제 유지 능력이 저하되었다. 대화를 원활히 이끌 어 나가기 위해서는 주어진 화제를 상대방과 주고받으면서 관련된 정보를 더하여 산출하는 것이 필요하다. 여기서 관련된 정보란 프 로토콜에서 제시된 주제와 관련된 이야기들을 의미하며 그 범위가 정해진 것은 아니지만 대화 상대자와의 공유된 지식이나 동의하에 서 다루어지는 정보를 의미한다. 따라서 정해진 정보의 큰 범위의 위계 내에서 다른 소주제로 전환시키며 대화를 이어나가는 것이 올 바른 화제전환이며 관련 없는 다른 주제로 벗어나게 되면 이는 화 제이탈이 되는 것이다. 관련된 주제에 대해 지속적으로 정보를 유 지하기 위한 작업기억력뿐만 아니라 대화 중 주제와 관련 없는 정 보들에 대한 억제능력, 화자가 주제를 변경할 때마다 해당 주제를 따라가기 위한 과제전환능력 등의 다양한 인지능력을 필요로 한다 (Lee \& Lim, 2014). 이러한 능력들 또한 전두엽의 집행기능에 해당 되는데(Douglas, 2010; Miller, 2000) FTD 환자의 경우 정상인보다 제한된 용량의 집행기능 자원을 가진 것(Mikesell, 2010)과 관련이 있을 수 있겠다. 즉, 대화의 내용이 논리적일수록 더 복잡한 정보들 을 분석하고 조작하여 판단해야 하기 때문에 주제를 분석하고 정 보를 조작하여 문제를 해결하는 능력이 제한된 집행기능 능력을 가진 FTD 환자의 경우 더 어려움을 보였을 가능성이 있다(Ash et al., 2006; Cosentino et al., 2006).

한편, DAT 환자가 대화화제 지표에서 FTD보다 높은 수행력을 보인 이유를 각 치매가 가지는 병변의 특성과 본 연구과제의 특성 에 근거하여 해석해볼 수도 있겠다. DAT 환자들은 어휘-의미 지식 을 담당하는 내측 측두엽 손상으로 의미적 오류가 나타난다. 따라 서, 이들은 단어에 대한 의미 지식이 상실되어 병의 초기부터 이름 대기장애가 두드러지게 나타나며(Lee \& Kim, 2011) 의미적인 오류 유형이 가장 흔하다(Lee \& Kim, 2011; Lim et al., 2014). 자발화 상 황에서도 의미 지식의 오류로 인한 어휘 인출 문제로 인하여 의미 착어를 보이거나 에두르기 혹은 대명사 사용을 많이 하는 것을 볼 수 있다. 그러나 본 연구에서 사용된 대화 과제에서는 큰 주제만 제 시될 뿐 반드시 산출해야 하는 정해진 목표 단어가 있는 것이 아니 므로 이름대기장애가 있더라도 다른 단어로 대체 산출하거나 대명 사 사용 또는 에두르기를 통해 이야기를 이어나갈 수 있다. 또한 본 연구에서는 대화의 각 지표에 대한 수행능력 분석 시 화용적인 부 분에 대한 평가에 중점을 두어 에두르기나 대명사 사용 부분에 대 하여 감점을 주지 않았다. 따라서 퇴행성 질환으로 인한 인지기능
의 감퇴를 보이지만 주로 의미적 오류를 보이는 DAT 환자는 대화 화제 지표에 있어서 정상인과 비교하여 저하되지 않은 수행력을 보 인 것으로 해석할 수 있다. 물론 DAT의 화용적인 어려움을 보고한 선행연구들도 다수 존재한다(Kim, 2012; Kim et al., 2006; Lee \& $\mathrm{Kim}, 2011)$. 그러나 이러한 선행연구들을 살펴보면, 중등도에 따라 DAT의 화용능력은 다양하게 나타날 수 있고 주로 초기에는 낱말 찾기 어려움에서 시작하여 병의 후기에 비로소 주제 운용능력이나 무의미 발화, 이해하기 어려운 에두르기가 관찰된다고 하였다(Müller \& Guendouzi, 2005). 이와 같은 맥락에서 초기 단계의 DAT의 화용능력은 대체적으로 보존된다는 연구결과가 보고되었다(Berrewaerts et al., 2003). 그러나, 추가적 분석을 통하여 화용적인 기술 에만 초점을 맞추는 것이 아니라 의사소통의 다양한 양상을 세분 화하여 분석할 필요도 있겠다.

\section{집단 간 대화방해 지표(대화차례 중단비율, 대화차례 중첩비율) 비교}

대화방해 지표에서는 집단 간 차이가 관찰되지 않았다. 일반적 으로 FTD 환자들은 충동조절을 담당하는 전두엽 안와 부위가 손 상되어 '탈억제' 증상이 나타나게 되는데, 예를 들어 부적절한 성적 인 발언이나 몸짓을 흔하게 보이며, 충동적이며 일의 결과를 생각 하지 않고 생각나는 대로 행동하거나 말한다고 알려져 있다(Neary et al., 1988). 때로는 이러한 충동적인 행동이 폭행이나 노출, 절도 와 같은 반사회적인 행동으로 나타나기도 한다. 이처럼 안와 부위 가 손상된 환자들은 사회적 상호작용 능력과 관련된 사회적 지식 과 기술의 어려움을 가지게 되므로(Gerardi-Caulton, 2000; Gregory et al., 2002), 대다수의 전두측두치매 환자들은 반복적으로 청 소를 하거나 충동적인 구매와 수집, 숫자 세기와 같이 상동행동 혹 은 보속적인 행동을 흔하게 보인다. 따라서 이러한 사회적 상호작 용 능력의 어려움이 대화 상황 내에서 어떠한 양상으로 나타나는 지 관찰하기 위하여 본 연구에서는 상대방의 말에 끼어들기 등을 반영하는 중첩 비율을 측정하였으나 정상 집단과의 유의미한 차이 를 보이지 않았다. 또한, 안와 부위가 손상된 FTD 환자들이 충동조 절에 어려움을 보이면서 필요 이상으로 대화 시 말을 많이 하는 양 상으로 발현되기도 하나(Kim, 2001) 본 연구의 대상자들에서는 이 러한 양상이 관찰되지 않았다. 중단 비율의 경우에도 집단 간 차이 가 관찰되지 않았으나 소수의 FTD 사례에서만 대화 도중 “하기 싫 어, 그만해”라고 하며 중단하는 양상이 관찰되었다. 이러한 양상은 전두엽 내측 부위의 손상에 기인한 동기 부족의 영향일 가능성이 있다.

본 연구에서는 기본적인 인지기능을 반영하는 K-MMSE 점수상 
차이를 보이지 않았던 DAT와 FTD 집단의 대화능력 비교를 통하 여 화용적인 측면의 감퇴가 반영된 FTD의 대화 특성을 확인할 수 있었다. 이는 임상적 활용의 측면에서, DAT 초기 환자들의 언어적 인 특징이 의미 손상에 기인한 이름대기장애인 반면에 초기 FTD 환자들은 대화 내에서 현저하게 적은 발화를 산출하고 대화에 참 여하는 빈도가 적으며 대화 내에서 화제를 응집력 있게 유지하지 못하여 자주 화제에서 벗어난 발화를 보이는 것 등의 화용적인 양 상을 확인하는 것이 중요함을 시사한다. 본 연구에 참여한 환자 대 상자는 10 명으로 그 결과를 일반화하기에 어려움이 있지만, 이러한 연구결과는 그동안 소수의 증례 관찰만을 통해 보고된 FTD 환자 군의 담화 능력을 뒷받침하면서 화용 및 대화적 측면에서의 FTD 특성을 제시한 최초의 연구로서 임상적 의의가 있다. 추후 대단위 의 대상자를 통한 확대 연구가 이루어진다면, 본 대화 특성들에 대 한 기준이 FTD 진단에 필요한 감별 정보의 하나로 활용될 수 있을 것이다. 또한, 추후 연구에서는 감별진단의 토대를 마련하기 위해 뇌영상 기법 등의 분석을 통하여 대상자들의 대화 특성이나 각 지 표와 관련이 있는 병소를 확인하고 대상자의 전두엽 기능부전에 대한 행동 특성을 수량화하여 대화 능력과 행동 양상 및 신경해부 학적 관련성에 대한 심도 있는 관찰이 필요하겠다.

\section{REFERENCES}

Abbeduto, L., \& Hesketh, L. J. (1997). Pragmatic development in individuals with mental retardation: Learning to use language in social interactions. Developmental Disabilities Research Reviews, 3, 323-333.

Adams, C., \& Bishop, D. V. (1989). Conversational characteristics of children with semantic-pragmatic disorder. I. Exchange structure, turntaking, repairs and cohesion. British Journal of Disorders of Communication, 24, 211239.

American Psychiatric Association. (2000). Diagnostic and Statistical Manual of mental disorders-fourth edition: text revision (DSM-IV-TR). Washington, DC: Author.

Ash, S., Moore, P., Antani, S., McCawley, G., Work, M., \& Grossman, M. (2006). Trying to tell a tale: discourse impairments in progressive aphasia and frontotemporal dementia. Neurology, 66, 1405-1413.

Assal, F., \& Ghika, J. (2013). Language capacities in dementia. Swiss Archives of Neurology and Psychiatry and Psychotherapy, 164, 280-285.

Berrewaerts, J., Hupet, M., \& Feyereisen, P. (2003). Langage et démence: examen des capacités pragmatiques dans la maladie d'Alzheimer. Revue de Neuropsychol, 13, 165-207.
Bishop, D. V., Chan, J., Adams, C., Hartley, J., \& Weir, F. (2000). Conversational responsiveness in specific language impairment: evidence of disproportionate pragmatic difficulties in a subset of children. Development and Psychopathology, 12, 177-199.

Braver, T. S., Satpute, A. B., Rush, B. K., Racine, C. A., \& Barch, D. M. (2005). Context processing and context maintenance in healthy aging and early stage dementia of the Alzheimer's type. Psychology and Aging, 20, 33-46.

Brinton, B., \& Fujiki, M. (1984). Development of topic manipulation skills in discourse. Journal of Speech, Language, and Hearing Research, 27, 350-358.

Brinton, B., Fujiki, M., \& Powell, J. M. (1997). The ability of children with language impairment to manipulate topic in a structured task. Language, Speech, and Hearing Services in Schools, 28, 3-11.

Bryan, T., Donahue, M., Pearl, R., \& Sturm, C. (1981). Learning disabled children's conversational skills: the 'TV Talk Show'. Learning Disability Quarterly, 4, 250-259.

Cappa, S. F., Binetti, G., Pezzini, A., Padovani, A., Rozzini, L., \& Trabucchi, M. (1998). Object and action naming in Alzheimer's disease and frontotemporal dementia. Neurology, 50, 351-355.

Carlomagno, S., Santoro, A., Menditti, A., Pandolfi, M., \& Marini, A. (2005). Referential communication in Alzheimer's type dementia. Cortex, 41, 520534 .

Channon, S., \& Watts, M. (2003). Pragmatic language interpretation after closed head injury: relationship to executive functioning. Cognitive Neuropsychiatry, 8, 243-260.

Choi, H. (2010). Category-specific impairment of patients with dementia of Alzheimer's type in category fluency tasks. Korean Journal of Communication \& Disorders, 15, 572-580.

Choi, J., \& Lee, Y. (2013). Conversational turn-taking and topic manipulation skills of children with high-functioning autism spectrum disorders. Communication Sciences \& Disorders, 18, 12-23.

Choi, J., \& Lee, Y. (2015). Contingency and informativeness of topic maintenance in children with high-functioning autism spectrum disorders. Communication Sciences \& Disorders, 20, 413-423.

Choi, S. H., Na, D. L., Lee, B. H., Hahm, D. S., Jeong, J. H., Jeong, Y., ... \& Korean Dementia Research Group. (2002). The validity of the Korean version of Global Deterioration Scale. Journal of the Korean Neurological Association, 20, 612-617.

Choi, Y. M., \& Jeon, B. U. (2003). An analysis of turn-taking of children with mental retardation. Korean Journal of Communication \& Disorders, 8, 8296. 
Christensen, K. J., Multhaup, K. S., Nordstrom, S., \& Voss, K. (1991). A cognitive battery for dementia: development and measurement characteristics. Psychological Assessment: A Journal of Consulting and Clinical Psychology, 3, 168-174.

Cosentino, S., Chute, D., Libon, D., Moore, P., \& Grossman, M. (2006). How does the brain support script comprehension? A study of executive processes and semantic knowledge in dementia. Neuropsychology, 20, 307-318.

Cotelli, M., Borroni, B., Manenti, R., Alberici, A., Calabria, M., Agosti, C., ... \& Zanetti, O. (2006). Action and object naming in frontotemporal dementia, progressive supranuclear palsy, and corticobasal degeneration. Neuropsychology, 20, 558-565.

Craig, H. K., \& Evans, J. L. (1989). Turn exchange characteristics of SLI children's simultaneous and nonsimultaneous speech. Journal of Speech and Hearing Disorders, 54, 334-347.

Crystal, D., Fletcher, P., \& Garman, M. (1976). The grammatical analysis of language disability: a procedure for assessment and remediation. London: Edward Arnold.

Cummings, J. L. (1993). Frontal-subcortical circuits and human behavior. Archives of Neurology, 50, 873-873.

Cummings, J. L. (2003). The neuropsychiatry of Alzheimer's disease and related dementias. London: Taylor \& Francis.

Cummings, J. L., Mega, M., Gray, K., Rosenberg-Thompson, S., Carusi, D. A., \& Gornbein, J. (1994). The Neuropsychiatric Inventory comprehensive assessment of psychopathology in dementia. Neurology, 44, 2308-2308.

Damasio, A. R., \& Anderson, S. W. (1993). The frontal lobes. In K. M. Heilman \& E. Valenstein (Eds.), Clinical neuropsychology (pp. 404-446). New York, NY: Oxford University Press.

Douglas, J. M. (2010). Relation of executive functioning to pragmatic outcome following severe traumatic brain injury. Journal of Speech, Language, and Hearing Research, 53, 365-382.

Douglas, J. M., Bracy, C. A., \& Snow, P. C. (2007). Exploring the factor structure of the La Trobe Communication Questionnaire: insights into the nature of communication deficits following traumatic brain injury. Aphasiology, 21, 1181-1194.

Dubois, B., Feldman, H. H., Jacova, C., DeKosky, S. T., Barberger-Gateau, P., Cummings, J., ... \& Meguro, K. (2007). Research criteria for the diagnosis of Alzheimer's disease: revising the NINCDS-ADRDA criteria. The Lancet Neurology, 6, 734-746.

Duffy, J. D., \& Campbell, J. J. (1994). The regional prefrontal syndromes: a theoretical and clinical overview. The Journal of Neuropsychiatry and Clini- cal Neurosciences, 6, 379-387.

Edmonds, P. E., \& Haynes, W. O. (1988). Topic manipulation and conversational participation as a function of familiarity in school-age language-impaired and normal language peers. Journal of Communication Disorders, 21, 209-228.

Evans, J. L., \& Craig, H. K. (1992). Language sample collection and analysis: interview compared to freeplay assessment contexts. Journal of Speech, Language, and Hearing Research, 35, 343-353.

Filley, C. M. (1995). Alzheimer's disease: it's irreversible but not untreatable. Geriatrics (Basel, Switzerland), 50, 18-23.

Gerardi-Caulton, G. (2000). Sensitivity to spatial conflict and the development of self-regulation in children 24-36 months of age. Developmental Science, 3, 397-404.

Gregory, C., Lough, S., Stone, V., Erzinclioglu, S., Martin, L., Baron-Cohen, S., \& Hodges, J. R. (2002). Theory of mind in patients with frontal variant frontotemporal dementia and Alzheimer's disease: theoretical and practical implications. Brain, 125, 752-764.

Grossman, M., D’Esposito, M., Hughes, E., Onishi, K., Biassou, N., WhiteDevine, T., \& Robinson, K. M. (1996). Language comprehension profiles in Alzheimer's disease, multi-infarct dementia, and frontotemporal degeneration. Neurology, 47, 183-189.

Health Insurance Review \& Assessment Service. (2016). 2016 health insurance statistics annual report. Retrieved from http://hira.or.kr/dummy. do?pgmid=HIRAA020041000000

Heo, H., \& Lee, Y. (2012). Conversational turn-taking and topic manipulation skills in conversations of school-age low-achievers in language learning. Korean Journal of Communication \& Disorders, 17, 66-78.

Hong, J. S., Heo, H., \& Lee, Y. (2012). Turn-taking characteristics of children with cochlear implant (CI). Journal of Speech \& Hearing Disorders, 21, 243259.

Hong, U., \& Lee, Y. (2016). Conversational characteristics of children with a mild intellectual disability. Special Education Research, 15, 111-126.

Jun, B. S., \& Park, J. H. (2016). Frontotemporal dementia. Journal of Korean Society of Biological Psychiatry, 23, 69-79.

Kang, Y. (2006). A normative study of the Korean-Mini Mental State Examination (K-MMSE) in the elderly. Korean Journal of Psychology: General, $25,1-12$.

Kee, B. S. (1996). A preliminary study for the standardization of geriatric depression scale short form-Korea version. Journal of the Korean Neuropsychiatric Association, 35, 298-307. 
Kim, H. K. (2001). Clinical evaluation of the frontal lobe syndrome using Kims frontal-executive neuropsychological test. Korean Journal of Rehabilitation Psychology, 8, 173-190.

Kim, J. W. (2012). Linguistic features of spontaneous speech production in normal aging and Alzheimer's disease. Journal of the Korea Gerontological Society, 32, 747-758.

Kim, J., Kim, H., Namkoong, K., Kim, S., \& Kim, D. (2006). Spontaneous speech traits in patients with Alzheimer's disease. Korean Journal of Communication \& Disorders, 11, 82-98.

Kim, S. E., \& Lee, Y. (2007). Conversation characteristics of children with attention deficit hyperactivity disorder. Korean Journal of Communication \& Disorders, 12, 662-675.

Kim, Y. T. (1997). Study of MLU in Korean 2-4 years children. Korean Journal of Communication \& Disorders, 2, 5-25.

Lee, H. J., \& Kim, Y. T. (2001). Turn-taking characteristics of children with specific language impairment and normal children. Korean Journal of Communication \& Disorders, 6, 293-312.

Lee, M. H., \& Lim, D. S. (2014). The pragmatic language ability and executive functions in children with ADHD: comparison with normal controls. Special Education Research, 13, 89-105.

Lee, M. S., \& Kim, H. (2011). Characteristics of expressive language in normal aging, mild cognitive impairment, and Alzheimer's disease. Dement Neurocognitive Disord, 10, 69-79.

Lee, M. S., \& Kim, H. (2013). Cognitive-pragmatic Language Ability Assessment Protocol for Traumatic Brain Injury (CAPTBI): reliability and validity. The Journal of the Korea Contents Association, 13, 370-377.

Lee, Y., \& Choi, J. (2018). Hallym Conversation and Pragmatic Assessment Protocol. Manuscript in preparation.

Lim, S., Kwon, M., Sim, H. S., Kim, S., \& Lee, J. Y. (2014). Word definition ability in patients with Alzheimer's disease. Dementia and Neurocognitive Disorders, 13, 7-15.

Luo, F., \& Timler, G. R. (2008). Narrative organization skills in children with attention deficit hyperactivity disorder and language impairment: application of the causal network model. Clinical Linguistics \& Phonetics, 22, 2546.

Menichelli, A., Rapp, B., \& Semenza, C. (2008). Allographic agraphia: a case study. Cortex, 44, 861-868.

Mentis, M. (1994). Topic management in discourse: assessment and intervention. Topics in Language Disorders, 14, 29-54.

Mikesell, L. (2010). Repetitional responses in frontotemporal dementia dis- course: asserting agency or demonstrating confusion? Discourse Studies, 12, 465-500.

Miller, E. K. (2000). The prefontral cortex and cognitive control. Nature Reviews Neuroscience, 1, 59-65.

Morris, J. C. (1993). The Clinical Dementia Rating (CDR): current version and scoring rules. Neurology, 43, 2412-2414.

Müller, N., \& Guendouzi, J. A. (2005). Order and disorder in conversation: encounters with dementia of the Alzheimer's type. Clinical Linguistics \& Phonetics, 19, 393-404.

Müller, N., \& Wilson, B. T. (2008). Collaborative role construction in a conversation with dementia: an application of systemic functional linguistics. Clinical Linguistics \& Phonetics, 22, 767-774.

Neary, D., Snowden, J. S., Northen, B., \& Goulding, P. (1988). Dementia of frontal lobe type. Journal of Neurology, Neurosurgery \& Psychiatry, 51, 353361.

Oh, H. G., Choi, H., \& Kim, S. (2010). Differences of language impairment related to semantic memory in patients with Alzheimer disease and vascular dementia. Journal of Speech \& Hearing Disorders, 19, 73-84.

Orange, J. B., Kertesz, A., \& Peacock, J. (1998). Pragmatics in frontal lobe dementia and primary progressive aphasia. Journal of Neurolinguistics, 11, 153-177.

Owens, R. E. (2004). Language disorder: a functional approach to assessment and intervention (4th ed.). Boston, MA: Allyn \& Bacon.

Park, Y. J., Choi, J. E., \& Lee, Y. (2017). Development of topic management skills in conversation of school-aged children. Communication Sciences \& Disorders, 22, 25-34.

Perkins, M. R. (2005). Pragmatic ability and disability as emergent phenomena. Clinical Linguistics \& Phonetics, 19, 367-377.

Perry, R. H., Dockray, G. J., Dimaline, R., Perry, E. K., Blessed, G., \& Tomlinson, B. E. (1981). Neuropeptides in Alzheimer's disease, depression and schizophrenia: a post mortem analysis of vasoactive intestinal peptide and cholecystokinin in cerebral cortex. Journal of the Neurological Sciences, 51, 465-472.

Prutting, C. A., \& Kittchner, D. M. (1987). A clinical appraisal of the pragmatic aspects of language. Journal of Speech and Hearing Disorders, 52, 105119.

Rascovsky, K., Hodges, J. R., Knopman, D., Mendez, M. F., Kramer, J. H., Neuhaus, J., ... \& Hillis, A. E. (2011). Sensitivity of revised diagnostic criteria for the behavioural variant of frontotemporal dementia. Brain, 134, 24562477. 
Schober-Peterson, D., \& Johnson, C. J. (1993). The performance of eight-to ten-year-olds on measures of conversational skilfulness. First Language, $13,249-269$.

Swartz, J. R., Miller, B. L., Lesser, I. M., Booth, R., Darby, A., Wohl, M., \& Benson, D. F. (1997). Behavioral phenomenology in Alzheimer's disease, frontotemporal dementia, and late-life depression: a retrospective analysis. Journal of Geriatric Psychiatry and Neurology, 10, 67-74.

Tallberg, I. M. (2007). Confabulation in dementia: constantly compensating memory systems. Neuropsychoanalysis, 9, 5-17.

Vuorinen, E., Laine, M., \& Rinne, J. (2000). Common pattern of language impairment in vascular dementia and in Alzheimer disease. Alzheimer
Disease \& Associated Disorders, 14, 81-86.

Wetherby, A. M., \& Rodriguez, G. P. (1992). Measurement of communicative intentions in normally developing children during structured and unstructured contexts. Journal of Speech, Language, and Hearing Research, 35, 130138.

Weiner, S. L., \& Goodenough, D. R. (1977). A move toward a psychology of conversation. Discourse Production and Comprehension, 1, 213-224.

Yoon, S. J., Jeong, J. H., Kang, S. J., \& Na, D. L. (2000). Compulsive behaviors and presenting symptoms of frontotemporal dementia. Journal of the Korean Neurological Association, 18, 681-686. 
Appendix 1. 대화 프로토콜 주제

\begin{tabular}{|l|l|}
\hline \multicolumn{1}{|c|}{ 가정생활 } & \multicolumn{1}{c|}{ 여가생활 } \\
\hline 1. "가족들과 주말에는 뭐 하면서 지내세요?" & 1. "휴식시간에는 주로 뭐 하면서 지내세요?" \\
\hline 2. "가족들과 생일에는 뭐 하면서 지내세요?" & 2. "특별히 취미활동 하시는 거 있으세요?" \\
\hline 3. "가족들과 추석/설날에는 뭐 하면서 지내세요?" & \\
\hline
\end{tabular}

Park, Choi, \& Lee (2017)의 프로토콜 주제를 수정 및 보완하였음.

Appendix 2. 발화구분 원칙

1. 1문장 1 발화를 원칙으로 한다.

2. 시간의 경과(대략 5 초 이상)나 두드러진 운율의 변화, 주제의 변화가 있을 때는 발화 수를 나눈다.

3. 같은 말이라도 다른 상황이나 문맥에서 표현되거나, 새로운 의미로 표현되었을 때에는 다른 발화로 취급한다.

4. 대상자가 스스로 수정하거나 새로운 의미의 첨가 없이 낱말이나 구를 반복할 때는 한 문장 안에 넣되 ()로 구분하고 분석에서 제외한다.

5. 아이가 습관적으로 (샘플자료의 $10 \%$ 이상 발화) 사용하는 간투어는 분석에서 제외시킨다.

6. '아' '오' 등의 감탄하는 소리나 문장을 이어가기 위한 무의미 소리들(예: 음, 어 등의 말이음)은 분석에서 제외시킨다.

7. 노래하기, 숫자세기 등과 같이 외워진 자동구어는 발화로 구분하지 않고 분석에서 제외시킨다. 그러나 발화 속에 이러한 자동구어가 내포되어 있을 경우에는 하나의 낱말로 보고 분석에 포함시킨다.

$\operatorname{Kim}(1997)$.

Appendix 3. 대화차례 정의 및 구분원칙

$$
\text { 내용 }
$$

1. 한 대화차례는 한 화자가 말을 시작하여 대화상대자가 말을 시작하기 전까지를 말하며 하나 이상의 발화가 포함될 수 있다(Adams \& Bishop, 1989; Bishop, Chan, Adams, Hartley, \& Weir, 2000; Bryan, Donahue, Pearl, \& Sturm, 1981; Kim \& Lee, 2007).

2. 대상자가 자신의 말 차례에 대화 화제를 변경하는 경우 대화차례를 나눈다(Kim \& Lee, 2007; Schober-Peterson \& Johnson, 1993).

3. 동일한 화제로 대화차례를 이어나갈 때, 발화 중에 3초 이상 쉼이 나타나는 경우에는 서로 다른 대화차례로 구분한다(Kim \& Lee, 2007; Lee \& Kim, 2001).

4. 대상자가 자신의 대화차례에서 맞장구 등의 낱말이나 구로 말한 경우에도 하나의 대화차례로 인정한다(Crystal, Fletcher, \& Garman, 1976).

5. 대상자가 단순히 상대방의 말을 듣고 있다는 추임새로서 머리 끄덕이기, 고개 젓기, 가리키기 등의 비구어적 행동은 대화차례로 보지 않으나, 대화 상대방의 질문이 나 지시에 자연스럽게 상대방에게 대화차례를 넘기는 기능을 가지는 발성 및 행동의 경우에는 하나의 대화차례로 간주한다(Adams \& Bishop, 1989; Bishop et al., 2000; Weiner \& Goodenough, 1977).

Heo \& Lee (2012)의 내용을 수정 및 보완하였음. 
Appendix 4. 주제 정의 및 세부 구분 원칙

1. 주제란 대화의 단위로 서로 연관된 일련의 발화로 이루어진다(Schober-Peterson \& Johnson, 1993).

2. 새롭게 주제를 개시하거나 변경하는 경우, 이미 소개된 주제로 동일한 어휘, 동일한 주제어(theme), 동일한 개념(concept) 또는 구성요소로 연결된 경우를 하나의 주제로 한다(Schober-Peterson \& Johnson, 1993).

주제 측정의 구체적인 정의는 다음과 같다.

1. 새롭게 화제가 개시된 후 새로운 화제로 변경되기 전까지 이어진 발화는 하나의 화제로 측정한다.

2. 이미 언급된 화제에 대해 정교화하거나 내용을 첨가하는 경우에는 별도의 화제로 측정하지 않는다.

3. 하나의 화제가 종료되고 다른 화제로 변경되었다가 다시 이전 화제로 언급한 경우에도 새로운 화제로 측정하지 않는다.

Schober-Peterson \& Johnson (1993)의 내용을 수정 및 보완하였음.

Appendix 5. 주제운용기술의 유형(주제 유지, 주제 변경) 및 방해지표의 유형(중첩, 중단)별 정의

\begin{tabular}{ll}
\hline 구분 & \multicolumn{1}{c}{ 정의 } \\
\hline 주제 유지 & 이전 대화차례에서 개시된 주제와 관련된 내용을 반복, 간단한 정보 또는 세밀한 의미를 추가하면서 대화차례를 이어나가는 경우이다(Briton \& \\
& Fujiki, 1984; Mentis, 1994; Prutting \& Kittchner, 1987). \\
& (1) 어휘로 연결된 경우 \\
& (2) 주제(theme)로 연결된 경우 \\
& (3) 개념(concept)이나 구성요소로 연결된 경우 \\
& 주제변경은 대화를 이어나가는 도중 이전 대화차례의 주제와 연결되지 않거나 자신의 이전 발화에서 새로운 주제로 대화 주제가 바뀌는 경우이 \\
& 다(Briton \& Fujiki, 1984; Prutting \& Kittchner, 1987; Mentis, 1994). 본 연구에서는 주제 변경을 이전 대화 차례의 주제와 관련성 있는 새로 \\
주제 변경 & 운 소주제로 바뀌는 경우 주제 전환으로, 전혀 관련 없는 주제로 바뀌는 경우 주제 이탈로 하였다. \\
& 대상자가 타인이 말을 하는 동안 말에 끼어들어 방해한 경우 \\
& 대화 도중 임의적으로 대상자가 대화를 중단시켜 대화흐름이 중단된 경우 \\
중첩 & 중단
\end{tabular}

Choi \& Lee (2013)의 정의를 수정 및 보완하였음.

Appendix 6. 대화상황에서의 각 집단의 발화 예시

\begin{tabular}{|c|c|c|}
\hline $\begin{array}{c}\text { 정상 성인(76세, 남) } \\
\text { 〈가정생활 주제〉 }\end{array}$ & $\begin{array}{c}\text { 알츠하이머성 치매(73세, 남) } \\
\text { <여가생활 주제〉 }\end{array}$ & $\begin{array}{l}\text { 전두측두치매(72세, 남) } \\
\text { 〈가정생활 주제〉 }\end{array}$ \\
\hline 검: 대화를 시작할게요. & 검: 대화를 시작할게요. & 검: 대화를 시작할게요. \\
\hline 대: 우리도 가족사진 많이 찍었지. & 대: 나도 산에 자주 가요. & 대: (무반응) \\
\hline 대: 젊었을때 많이 찍었는데 요즘엔 다들 바쁜 세상이 & 검: 산에 자주 가시는구나. & 검: 가정생활은 어떠세요? \\
\hline 라 찍은 기억이 가물가물 하네. & 대: 사우나도 자주 가구요. & 대: 몰라 \\
\hline 대: 아무튼 나는 어려서부터 대가족으로 살았고 지금 & 대: 소금 사우나에 간 적이 있어요. & 검: 주말에 가족분들하고는 뭐 하세요? \\
\hline 도 며느리랑 아들이랑 같이 사는데 참 좋아. & 대: 그때 되게 좋았던 기억이 나네요. & 대:교회 \\
\hline \multirow{5}{*}{$\begin{array}{l}\text { 대: 주말이면 여기저기 데려가주고 맛있는거 사주는 } \\
\text { 데 참 고마워. }\end{array}$} & 대: 사우나 원래는 별로 안 좋아했는데 소금 사우나는 & 검: 교회 가시는구나(3초 쉬고) 그리고요? \\
\hline & 좋더라구요. & 대:안 해 \\
\hline & 대: 그래서 더 생각이 나. & 검: 생일에는요 아버님? \\
\hline & & 대: 고스톱 \\
\hline & & 대: 하기 싫어 그만해. \\
\hline
\end{tabular}

검=검사자; 대=대상자. 


\section{국문초록}

\section{전두측두치매환자의 대화 특성: 알츠하이머성 치매와의 비교}

민준상 ${ }^{1}$ 윤지혜 ${ }^{2} \cdot$ 나덕렬 3 - 이윤경 ${ }^{2}$

'한림대학교 대학원 언어병리청각학과, ${ }^{2}$ 한림대학교 언어청각학부, ${ }^{3}$ 성균관대학교 의과대학 삼성서울병원 신경과

배경 및 목적: 전두측두치매(FTD) 환자는 전두엽의 전반적인 손상으로 인해 병의 초기부터 대화 시 화용적인 어려움을 보인다. 본 연 구는 알츠하이머성 치매(DAT) 집단과의 비교를 통해 FTD 환자에서 두드러지는 대화 특성을 확인하였다. 방법: 총 50명(FTD 10명, $\mathrm{DAT} 20$ 명, 정상[NA] 20명)을 대상으로 다양한 주제에 대하여 자유롭게 대화하도록 하였다. 자료 분석은 대화참여 지표와 대화화제 지 표 및 대화방해 지표로 나누어 분석하였다. 결과: 첫째, 대화참여 측면에서 FTD 집단은 DAT, NA 집단보다 대화차례 주고받기 빈도와 대화차례당 발화 수 모두에서 유의하게 낮은 수행력을 보였다. 둘째, 대화화제 측면에서 FTD 집단은 DAT, NA 집단보다 화제 수, 화제 당 대화차례 빈도, 화제유지비율, 화제전환비율은 유의하게 낮았고 화제이탈비율은 유의하게 높았다. 셋째, 대화방해 측면에서 FTD 집 단은 DAT, NA 집단과 유의한 차이를 보이지 않았다. 논의 및 결론: 이러한 결과는 전두엽의 내측부위 손상으로 인한 동기부족으로 발 화 수가 적고, 배외측 부위 손상으로 인한 전반적인 언어처리 및 작업기억능력의 결함으로 다양한 화제를 개시하거나 화제를 유지하는 것에 어려움을 보인 것으로 해석해볼 수 있다.

핵심어: 전두측두치매, 대화, 주제운용, 주제유지

이 논문은 2017년 정부(산업통상자원부)의 재원으로 한국산업기술평가관리원의 지원을 받아 수행된 연구임(No. 10063384).

이 논문은 2017년도 한림 선도연구그룹지원사업(No. HRF-LGR-2017-0002)의 지원을 받아 연구되었음.

\section{참고문헌}

김홍근(2001). 전두엽 증후군의 임상 평가: Kims 전두엽관리기능 신경심리검사를 중심으로. 재활심리연구, 8, 173-190.

박윤정, 최지은, 이윤경(2017). 초등학생 아동의 대화 화제관리 능력의 발달. 언어청각장애연구, 22, 25-34.

오혜경, 최현주, 김수진(2010). 알츠하이머병과 혈관성 치매 환자의 의미기억과 관련된 언어과제의 수행 차이. 언어치료연구, 19, 73-84.

윤수진, 정지향, 강수진, 나덕렬(2000). 전두측두엽 치매의 강박적 행동과 초기 증상. 대한신경과학회지, 18, 681-686.

이강준(2012). 전두측두엽 치매의 임상 양상과 치료적 접근. 노인정신의학, 16, 67-74.

이윤경, 최지은(2018). 한림 대화·화용 평가 프로토콜. 출판예정.

최지은, 이윤경(2013). 학령기 고기능 자폐범주성장애 아동의 대화차례 주고받기 및 주제운용능력. 언어청각장애연구, 18, 12-23.

최지은, 이윤경(2015). 학령기 고기능 자폐스펙트럼장애 아동의 주제유지능력: 수반성과 정보성을 중심으로. 언어청각장애연구, 20, 413-423. 